\title{
Comparisons between abundance estimates from underwater visual census and catch-per-unit-effort in a patch reef system
}

\author{
Mandy Karnauskas ${ }^{1,2, *}$, Elizabeth A. Babcock ${ }^{1}$ \\ ${ }^{1}$ Rosenstiel School of Marine and Atmospheric Science, Department of Marine Biology and Fisheries, University of Miami, \\ Miami, Florida 33149, USA \\ ${ }^{2}$ Present address: Southeast Fisheries Science Center, National Marine Fisheries Service, NOAA, Miami, Florida 33149, USA
}

\begin{abstract}
Methods of underwater visual censuses (UVC) and catch-per-unit-effort (CPUE) are both commonly used to estimate abundance of fish stocks. While each method is subject to certain biases, in theory they should produce related measures of fish abundance for a specific site at a given point in time, for species targeted by both methods. We tested relationships between estimates of abundance and biomass from UVC and experimental hook-and-line CPUE in a spatially complex coral patch reef system. Fishes targeted by the CPUE method were significantly larger than those sampled by UVC. Abundance estimates from UVC and CPUE were significantly correlated when the data were collected simultaneously - and over small spatial scales $(<20 \mathrm{~m})$. However, this correlation was reduced when collection of UVC and CPUE data was separated by either time or space. Spatial autocorrelation in the fish community composition was not detected for most species, and abundance estimates were highly variable over time and space. Our results show that differences among monthly sampling periods were responsible for the greatest amount of variability in the data, and we recommend that abundance estimates should be derived from surveys carried out over multiple months to improve accuracy. While the UVC method is useful to detect a wide variety of species, some species are more efficiently assessed using CPUE. Development of cost-effective monitoring programs is crucial to document changes in reef fish populations and support the implementation of management regulations that may prevent further degradation of reef fisheries worldwide.
\end{abstract}

KEY WORDS: Commercial fish abundance - Coral reefs · Fisheries management - Sampling method $\cdot$ Spatial autocorrelation $\cdot$ SCUBA survey

Resale or republication not permitted without written consent of the publisher

\section{INTRODUCTION}

Detecting trends in abundance over time is at the heart of traditional fisheries assessment methods, while advances in spatial management have recently necessitated an increased understanding of patterns in abundance over space. One of the most common indices of abundance in fisheries management is catch-per-unit-effort (CPUE), and it is generally assumed that CPUE is proportional to stock abundance, despite wide recognition of the biases associ- ated with CPUE. For example, lack of proportionality between CPUE and abundance may result from hyperstability (Harley et al. 2001), spatial autocorrelation in the stock (Bordalo-Machado 2006), and variations in vessel and gear types (Ye \& Dennis 2009). Use of the underwater visual census (UVC) method to assess fish abundance has been common since the 1970s, particularly in assessments of reef systems (Connell et al. 1998). UVC is sometimes considered a less biased estimate of the true abundance, but it is also subject to biases such as diver attraction or 
avoidance (Bennett et al. 2009, Bozec et al. 2011), detectability (MacNeil et al. 2008), and diver error (Harvey et al. 2004), among many other factors (Bozec et al. 2011 and references within). Understanding the biases of different abundance estimation methods is essential to management and conservation (Eros et al. 2009).

While UVC and CPUE are both used as indices of abundance, relationships between them on a species-specific and site-specific basis have only been tested in a select few studies (Ralston et al. 1986, Richards \& Schnute 1986, Haggarty \& King 2006). Furthermore, we found only 2 instances where these relationships were tested in coral reef systems (Kulbicki 1988, Connell et al. 1998). These studies failed to find a proportional relationship between CPUE and UVC, except when the data were collected in the same place at the same time (Richards \& Schnute 1986, Kulbicki 1988), and even then only for some species (Haggarty \& King 2006). Because both CPUE and UVC are used as indices of stock abundance, it is necessary to identify biases which may cause a lack of correlations between the 2 methods.

Assessing abundance in reef systems is particularly challenging given the high habitat diversity, dynamic species-habitat interactions, and complex species behaviors (Acosta 1997). Local abundance of reef fishes is affected by multiple factors, such as topography (Pittman et al. 2009), coral cover (Bell \& Galzin 1984), and depth and exposure (Beger \& Possingham 2008). Garcia-Charton et al. (2004) showed that fish assemblages on Mediterranean reefs were patchy on scales of 10 s of meters to 100 s of kilometers, and patch reef configuration has been shown to influence fish assemblages in the Caribbean (Acosta \& Robertson 2002, Grober-Dunsmore et al. 2008). Other studies have found that spatial variability in reef systems is high enough to obscure management effects (Harborne et al. 2008, Huntington et al. 2010). Temporal variability in reef systems may result from diurnal movements (Friedlander \& Monaco 2007), spawning movements (Starr et al. 2007), and stochastic processes (McClanahan et al. 2007), all of which act on different temporal scales. The presence of marine reserves or protected areas may also change fish abundance and composition, as well as fish behavior (Januchowski-Hartley et al. 2011). For these reasons, indices of abundance for reef fishes are likely to be highly variable over space and time.

In this study, we tested relationships between UVC and experimental hook-and-line CPUE estimates of abundance in a spatially heterogeneous coral reef system. We tested the extent of correlations over varying scales of time and space, and clarify under which circumstances CPUE and UVC are related. The goal of the study was to elucidate the relative biases in each sampling method, and to make recommendations in regards to the applications of these 2 indices to different research questions. Previous studies have established that UVC and CPUE estimates of abundance are often poorly correlated in coral reef systems, but have not elucidated the reasons for this lack of correlation.

\section{MATERIALS AND METHODS}

\section{Study site}

We carried out our study within the lagoonal patch reefs at Glover's Reef Marine Reserve, located on an isolated atoll in Belize. The lagoon contains some 850 isolated patch reefs of varying sizes (Gischler \& Hudson 1998), and is surrounded by a reef crest barrier with the exception of 3 channels (Fig. 1). The entire 35000 ha atoll is a managed area with limited fishing-gear use, and one-fifth of the area was designated as a no-take zone in 1993 (Sobel \& Dahlgren 2004).

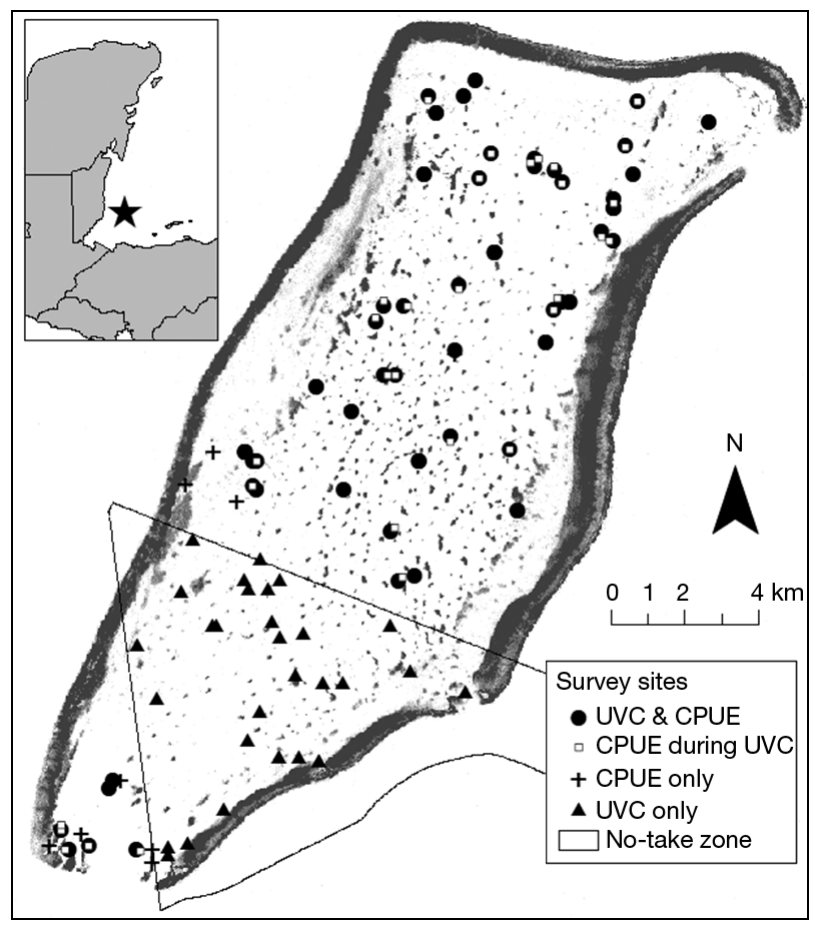

Fig. 1. Study site at Glover's Reef Marine Reserve, Belize, indicating location of underwater visual census (UVC) and catch-per-unit-effort (CPUE) data collection 


\section{Collection of UVC data}

From 2008 to 2009, fish abundance was assessed by UVC at 97 randomly selected patch reef sites using stationary point counts (Bohnsack \& Bannerot 1986; Table 1). Stationary point counts are better than belt transects at detecting larger, roving commercial species (e.g. barracuda, jacks, snappers, and groupers), which were the focus of our study (Murphy \& Jenkins 2010), and therefore the preferable method. A single diver recorded the abundance and length in $\mathrm{cm}$ of all commercially targeted fishes swimming through an imaginary $5 \mathrm{~m}$ cylinder in $5 \mathrm{~min}$. Counts were conducted on the $N, E, S$, and $W$ sides of the patch at the $3 \mathrm{~m}$ depth contour, and also at the patch center. At each site, visibility, weather conditions, and time of day were recorded. Average abundance at each site was calculated by averaging across the 5 sample cylinders.

\section{Collection of CPUE data}

CPUE data collection was partially undertaken in conjunction with another project where reef fishes were used as bait, and thus our sampling scheme is somewhat complex due to the opportunistic nature of some of the data collection. CPUE data were collected at each of the 49 dive sites occurring in the fished area of the atoll, by the same professional fisher who has experience at Glover's Reef. Each of these sites was replicated at least once, and additional replicates of some sites were carried out by different fishers (Table 1). We also collected CPUE data at a number of randomly selected non-dive sites. Specific subsets of the data that were used to carry out each analysis are detailed in Table 1; subsets of data were selected for each analysis to maximize sample size without grouping data from multiple fishers, so that results were not confounded by variability in fishing skill among fishers.

Table 1. Details of underwater visual census (UVC) and catch-per-unit-effort (CPUE) data collection. Numbers in square brackets $=$ sample size $[\mathrm{n}]$. Superscripts indicate subsets of data used to carry out various data analyses. When the entire sample was not used, numbers in parentheses following letters indicate number of samples. A: Spearman's rank correlations for UVC versus CPUE for (A1) CPUE and UVC data collected simultaneously, and (A2) CPUE and UVC collected on different days. B: perMANOVAs for correlations between UVC and CPUE for (B1) CPUE and UVC collected simultaneously, and (B2) CPUE and UVC collected on different days. C: perMANOVAs for correlations between UVC and CPUE for (C1) UVC estimates based on averages over 5 stationary point counts, and (C2) UVC estimates taken only from the stationary point count carried out on the side of the patch nearest the exact location where fishing took place. D: Spearman's rank correlations for UVC estimates of abundance in 2008 versus 2009 by species. E: Spearman's rank correlations for CPUE estimates of abundance in 2009 versus 2010 by species. F: ANOSIMs carried out on (F1) the set of UVC sites and (F2) the entire set of randomly selected CPUE sites. Calculations of occurrence rates and level of spatial autocorrelation were carried out on the full CPUE and UVC data sets

\begin{tabular}{|c|c|c|c|c|}
\hline \multicolumn{2}{|c|}{$\begin{array}{l}\text { UVC }\left[\mathbf{9 7}^{\mathrm{F} 1}\right. \\
\text { Year }\end{array}$} & \multicolumn{2}{|l|}{ Location } & Replication details \\
\hline \multicolumn{2}{|l|}{$2008[30]$} & \multicolumn{2}{|c|}{$\begin{array}{l}\text { Reserve }[11]^{\mathrm{D}(4)} \\
\text { Fished zone }[19]^{\mathrm{A} 2(14), \mathrm{C} 1 \& \mathrm{C} 2(12), \mathrm{D}(11)}\end{array}$} & \\
\hline \multirow{2}{*}{\multicolumn{2}{|c|}{2009 [67] }} & \multicolumn{2}{|l|}{ Reserve [23] } & $\begin{array}{l}2008 \text { replicates }[4]^{\mathrm{D}} \\
\text { Non-replicates }[19]\end{array}$ \\
\hline & & \multicolumn{2}{|c|}{ Fished zone $[44]^{\mathrm{A} 1(38), \mathrm{A} 2(35), \mathrm{B} 1 \& \mathrm{~B} 2(30), \mathrm{C} 1 \& \mathrm{C} 2(31)}$} & $\begin{array}{l}2008 \text { replicates }[11]^{\mathrm{D}} \\
\text { Non-replicates }[33]\end{array}$ \\
\hline \multicolumn{5}{|c|}{ CPUE $[125]^{\mathrm{F} 2}$} \\
\hline Year & Fisher & Miscellaneous details & Relation to UVC & Replication details \\
\hline $2009[62]$ & $1[62]$ & $\begin{array}{l}\text { Non-dive sites [12] } \\
\text { Dive sites [50] }]^{\mathrm{E}(41)} \\
\text { Exact depth recorded }\end{array}$ & UVC collected simultaneously [38] ${ }^{\mathrm{A} 1}$ & $\begin{array}{l}\text { Replicated sites [8] } \\
\text { Non-replicated sites [30] }{ }^{\mathrm{B} 1}\end{array}$ \\
\hline $2010[64]$ & $\begin{array}{l}1[4] \\
1 \& 6[49]^{\mathrm{A} 2}\end{array}$ & $\begin{array}{l}\text { Exact site location rec } \\
\text { Exact depth recorded }\end{array}$ & {$[43]^{\mathrm{C} 1 \& \mathrm{C} 2}$} & $\begin{array}{l}\text { Non-replicates [41] }{ }^{\mathrm{E}, \mathrm{B} 2(30)} \\
\text { Replicates [8] }\end{array}$ \\
\hline
\end{tabular}


To collect CPUE data at each patch reef site, fishers anchored as close to the patch as possible without damaging habitat and selected the specific side of the patch at which to anchor based on wind and current conditions. Experimental fishing was carried out with traditional hook and hand line gear, using locally acquired hooks approximately 5/0 in size and pieces of freshly caught herring as bait. Species and fork lengths of all captured fishes were recorded. Experimental fishing at randomly selected sites was carried out for $20 \mathrm{~min}$; this time period was chosen because it was approximately the average amount of time that fishers spent fishing at patch reef sites when unrestricted (M. Karnauskas unpubl. data). For all sites, the date, weather conditions, and time of day were recorded. For a subset of the experimental fishing samples, the exact depth where fishing occurred and the location (side of the patch) was recorded. Lengths were converted to biomass based on conversions for each species reported by Bohnsack \& Harper (1988); CPUE was standardized to ind. fisher $^{-1} \mathrm{~h}^{-1}$ and $\mathrm{kg}$ fisher ${ }^{-1} \mathrm{~h}^{-1}$.

For a subset of the sites sampled by experimental fishing, CPUE data were collected simultaneously with UVC data. While it is impossible to collect CPUE and UVC data at the exact same time and location without having 1 method bias the data collection of the other, we made an effort to sample as closely as possible in time and space while minimizing biases. Divers first entered the water and swam around the patch to begin sampling at a point where the fishing gear was not in view. Experimental fishing then commenced and CPUE data collection was carried out for the 20 min period, during which time the diver completed 2 to 3 UVC point counts. By the time the diver returned to complete the 5th stationary point count nearest the boat, CPUE data collection had been completed for about $10 \mathrm{~min}$.

\section{Data analyses}

We first calculated occurrence rates (\% of sites in which a species was present) for each of the UVC and CPUE methods using the full data set. Species with occurrence rates of $>20 \%$ in both survey methods were selected for further univariate and multivariate analyses. For the frequently occurring species, length frequency histograms were plotted for individuals observed in the UVC and CPUE. We used $t$-tests to examine whether differences in average lengths detected by the 2 methods were significant. For each species, we also calculated the ratio of max- imum length in the UVC versus maximum length in the CPUE, and the proportion of overlap in the cumulative frequencies of UVC versus CPUE. Relative selectivity of species in the hook-and-line catch versus the UVC counts was calculated as the ratio of the proportional abundance in the catch (i.e. the fraction that each species represented of the total catch) to the proportional abundance of the full set of species observed in the UVC counts (Hawkins et al. 2007). This value is an indication of the vulnerability of the species to the fishing gear, with higher relative selectivity values indicating that the species is more easily caught with hook-and-line.

Spearman's rank correlation tests were used to determine whether UVC and CPUE estimates were correlated, with individual sites as samples. We first carried out correlation tests on 3 community-level indices, based on the full set of species observed in both the UVC and CPUE: total species richness, total abundance, and total biomass. We then carried out these correlation tests on a species-specific basis for species with occurrence rates $>20 \%$ in both survey methods. Separate analyses were run for comparisons when CPUE and UVC data were collected simultaneously ( $\mathrm{n}=38$, analysis $\mathrm{A} 1$ ) and for when CPUE and UVC were collected on different days $(\mathrm{n}=$ 49, analysis A2). We then investigated the influence of size selectivity on correlations between abundance as estimated by CPUE and UVC methods. For each of the species-specific comparisons, we recalculated the correlations using either the full set of observations in the UVC data set, or the UVC data set after removing, for each species, the observations with lengths that were outside of the length range observed in the CPUE data. To assess our ability to detect correlations given our sample sizes, we developed power curves using the methods of Modarres (1996). Using the developed power curves, we estimated the power to detect correlations of $r=0.50, r=$ 0.30 , and $r=0.10$ given bootstrapped sample sizes ranging from 10 to 100 in intervals of 10 . Power curves were smoothed using a second-order local polynomial regression function.

To analyze correlations between community composition in species abundance and biomass based on UVC estimates versus CPUE estimates at different temporal and spatial scales, we used permutational multivariate analysis of variance (perMANOVA; Anderson 2001). The non-parametric form of MANOVA was used because assumptions of normality could not be met. All perMANOVAs in this study were based on the set of species with occurrence rates $>20 \%$, and tests were performed on matrices 
scaled by columns because the test is sensitive to differences in dispersion among groups (McCune \& Grace 2002). The Bray-Curtis distance measure was used, as it is suitable for quantifying ecological differences in community composition (Faith et al. 1987). For all tests, 999 permutations were carried out; the reported $\mathrm{p}$ values represent the percent of matrices where the $F$ values calculated from randomized matrices are greater than the observed $F$ value. All analyses were carried out in R version 2.7.2 (R Core Development Team, vegan library; Anderson 2001).

To investigate the effect of temporal differences on correlations between UVC and CPUE, we carried out perMANOVA for matrices of abundance and biomass estimates for CPUE and UVC collected simultaneously ( $\mathrm{n}=30$ sites, 5 species, analysis B1) and for CPUE and UVC collected in different years $(n=30$ sites, 5 species, analysis B2). To investigate the effect of spatial scales on correlations between UVC and CPUE estimates, we carried out perMANOVA on abundance and biomass estimates for CPUE and UVC where the estimates were based on averages over 5 stationary point counts $(\mathrm{n}=43,5$ species, analysis C1) and for CPUE and UVC where estimates were taken only from the stationary point count carried out on the side of the patch nearest the exact location where fishing took place ( $\mathrm{n}=43,5$ species, analysis C2). For each set of comparisons, the same sites were used to remove the effects of sample size on the strength of the correlation.

We also quantified the amount of variability within sampling methodologies, using comparisons of abundance estimates from the same sites over multiple time periods. We compared UVC estimates of abundance in 2008 versus 2009 by species, using Spearman's rank correlations ( $\mathrm{n}=15$ sites, analysis D). We also compared abundance estimates from CPUE for sites sampled in 2009 versus 2010 (Spearman's rank correlations, $\mathrm{n}=41$ sites, analysis E). To elucidate the sources of variability in community composition within sampling methodologies, we used analysis of similarity (ANOSIM; Clarke 1993) of the abundance matrix for the most frequently occurring species. We tested multiple variables (sampling period, date, weather conditions, time of day, underwater visibility, site location with respect to the no-take zone boundary, fisher, and depth) to determine which factor(s) was associated with the greatest amount of variability within the CPUE and UVC data, respectively. Sampling period was defined as month and year combination, weather conditions were classified as calm, moderate, windy, or very windy; time of day was defined as morning, noon, or afternoon; and underwater visibility was classified as low, medium, or high. ANOSIM was carried out separately for the entire set of UVC sites ( $\mathrm{n}=97,5$ species, analysis F1) and for the set of CPUE sites ( $\mathrm{n}=125,5$ species, analysis F2). Finally, we quantified the level of spatial autocorrelation in fish abundance present in this system based on the full set of UVC data, to elucidate at which spatial scales we might expect replicate observations to be correlated. Variograms were constructed for the most frequently occurring species using the classical method of moments estimator (R version 2.7.2, geoR library; Diggle \& Ribeiro 2007).

In order to compare sampling efficiency of the 2 sampling methods, we calculated minimum sample sizes necessary to detect an expected mean difference of $100 \%$ for each species (2-tailed $t$-test). We used the equation $\mathrm{n}=16 \mathrm{~s}^{2} / \Delta^{2}$ to calculate minimum sample size, where $s$ is the estimated standard deviation of the variable and $\Delta$ is the expected mean difference, and $\mathrm{n}$ gives the minimum sample size for a 2tailed $t$-test of $80 \%$ power at the 0.05 significance level (Lehr 1992). We calculated standard deviation of the abundances of individual species using all sites from 2009, as the majority of samples were collected in this year.

\section{RESULTS}

\section{Occurrence rates and gear selectivity}

The UVC method captured a total of 57 species with average body lengths $>5 \mathrm{~cm}, 18$ of which were observed in the CPUE. On average ( \pm SD), we detected $15.8 \pm 3.5$ species site $^{-1}$ in the UVC and $2.6 \pm 1.6$ species site ${ }^{-1}$ in the CPUE. In the UVC, an average of $36.1 \pm 28.2$ individual fish were detected per sample cylinder, and in the CPUE, an average of $15.8 \pm 13.2$ fish were caught per fisher-hour. In terms of biomass, UVC detected a total of $4.2 \pm 2.7 \mathrm{~kg}$ of fish per cylinder, while $4.6 \pm 3.9 \mathrm{~kg}$ of fish per fisher-hour were captured at CPUE sites. The most frequently occurring fish species in the experimental fishing data were, in order of occurrence: yellowtail snapper Ocyurus chrysurus, white grunt Haemulon plumierii, saucereye porgy Calamus calamus, lane snapper Lutjanus synagris, and mutton snapper $L$. analis. These 5 species were the only species to have occurrence rates of $>20 \%$ in the catch (Table 2). The top 5 most frequently occurring species in the UVC included $H$. plumierii and $O$. chrysurus, while the other 3 species (C. calamus, L. synagris, and L. analis) 
Table 2. Species occurring in the experimental catch-per-unit-effort (CPUE). Occurrence is calculated as the proportion of sites in which the species was observed. Relative selectivity is calculated as the ratio of the proportional abundance in the CPUE to the proportional abundance in the underwater visual census (UVC)

\begin{tabular}{|c|c|c|c|c|c|c|}
\hline \multirow[t]{2}{*}{ Scientific name } & \multirow[t]{2}{*}{ Common name } & \multicolumn{2}{|c|}{ CPUE- } & \multicolumn{2}{|c|}{$-\mathrm{UVC}-$} & \multirow{2}{*}{$\begin{array}{r}\text { Relative } \\
\text { selectivit }\end{array}$} \\
\hline & & Occurrence & Total n & Occurrence & Total n & \\
\hline Ocyurus chrysurus & Yellowtail snapper & 0.72 & 304 & 0.94 & 2926 & 0.92 \\
\hline Haemulon plumierii & White grunt & 0.50 & 154 & 0.92 & 2973 & 0.46 \\
\hline Calamus calamus & Saucereye porgy & 0.42 & 140 & 0.74 & 477 & 2.60 \\
\hline Lutjanus synagris & Lane snapper & 0.32 & 281 & 0.33 & 574 & 4.34 \\
\hline Lutjanus analis & Mutton snapper & 0.26 & 52 & 0.36 & 71 & 6.50 \\
\hline Epinephelus guttatus & Red hind & 0.14 & 29 & 0.28 & 55 & 4.68 \\
\hline Epinephelus cruentatus & Graysby & 0.08 & 14 & 0.42 & 131 & 0.95 \\
\hline Epinephelus morio & Red grouper & 0.08 & 12 & 0.20 & 26 & 4.09 \\
\hline Lutjanus apodus & Schoolmaster & 0.04 & 6 & 0.51 & 149 & 0.36 \\
\hline Lutjanus griseus & Gray snapper & 0.02 & 2 & 0.18 & 135 & 0.13 \\
\hline Caranx ruber & Bar jack & 0.02 & 2 & 0.83 & 1095 & 0.02 \\
\hline Haemulon sciurus & Bluestriped grunt & 0.02 & 2 & 0.52 & 276 & 0.06 \\
\hline Canthidermis sufflamen & Ocean trigger & 0.01 & 1 & 0.01 & 1 & 8.87 \\
\hline Caranx crysos & Blue runner & 0.01 & 2 & 0.00 & 0 & NA \\
\hline Lutjanus mahogoni & Mahogany snapper & 0.01 & 1 & 0.06 & 9 & 0.99 \\
\hline Epinephelus striatus & Nassau grouper & 0.01 & 1 & 0.27 & 5 & 1.77 \\
\hline Mycteroperca tigris & Tiger grouper & 0.01 & 1 & 0.01 & 1 & 8.87 \\
\hline
\end{tabular}

were well represented with occurrence rates of $>33 \%$. The majority of the 42 commercially valuable species observed in the UVC (such as parrotfishes and angelfishes) were not caught by hook-and-line. The species with the highest relative selectivity values were Canthidermis sufflamen and Mycteroperca tigris, although these estimates may be inaccurate as they are based on low sample sizes (Table 2). Other species with high selectivity values included snappers and groupers (L. analis, Epinephelus guttatus, E. morio, and L. synagris).

The average length of captured fish was greater than the average length observed in the UVC. For the 5 most frequently occurring species in the CPUE data, only the larger size classes observed in the UVC counts appeared in the hook-and-line catch (Fig. 2). Differences in length between individuals observed in UVC and those caught in the CPUE were significant for all species $(\mathrm{p}<0.001)$ except Lutjanus analis $(\mathrm{p}=0.02)$.

\section{Species-specific correlations between UVC and CPUE}

When UVC and CPUE data were collected simultaneously, estimates of total abundance of the full set of
Table 3. p-values for Spearman's rank correlations of fish abundance estimates from underwater visual census (UVC) and catch-per-unit-effort (CPUE). between CPUE and the entire UVC data set; the correlations under 'fished sizes' refer to correlations between CPUE and the UVC data set excluding non-fished size classes

\begin{tabular}{|lcccr|}
\hline Species & \multicolumn{2}{c|}{$\begin{array}{c}\text { Simultaneous } \\
\text { CPUE \& UVC }\end{array}$} & \multicolumn{2}{c|}{$\begin{array}{c}\text { CPUE \& UVC } \\
\text { different days }\end{array}$} \\
& Full data set Fished sizes & Full data set Fished sizes \\
\hline Lutjanus synagris & 0.29 & 0.29 & $<0.01$ & $<0.01$ \\
Ocyurus chrysurus & $<0.001$ & $<0.001$ & 0.75 & 0.37 \\
Calamus calamus & 0.42 & 0.99 & 0.55 & 0.64 \\
Haemulon plumierii & 0.72 & 0.73 & 0.85 & 0.98 \\
Lutjanus analis & 0.05 & 0.05 & 0.98 & 0.98 \\
\hline
\end{tabular}

species detected in both survey methods were correlated ( $p<0.01)$, but estimates of biomass $(p=0.07)$ and species richness $(p=0.17)$ were not correlated. However, when UVC and CPUE data were collected on different days, estimates of abundance $(p=0.26)$ and biomass $(p=0.68)$ were not correlated, although estimates of richness were marginally correlated $(\mathrm{p}=$ 0.05). In the single-species analysis, UVC and CPUE were correlated across sites for 2 species: Ocyurus chrysurus and Lutjanus synagris; however, the correlations occurred only under specific circumstances (Table 3). For O. chrysurus, CPUE and UVC were correlated only when data were collected simultaneously, but for L. synagris, the 2 methods were corre- 
lated only when data were collected on different days. Accounting for size selectivity, by removing from the UVC data set size classes of each species that did not appear in the CPUE, did not have any effect on improving the correlations between estimates of abundance (Table 3). For the sample sizes used in our analyses, power to detect a correlation of 0.50 was at least 0.60 for all species and was $>0.80$ for 3 species (Fig. 3).

\section{Temporal and spatial scales of variability in estimates}

When CPUE and UVC were collected simultaneously for the same patch, perMANOVA showed that species composition in terms of abundance of the top 5 species was significantly correlated between CPUE and UVC samples ( $\left.p=0.02, r^{2}=0.29\right)$. However, community structure in terms of biomass was not signifi-
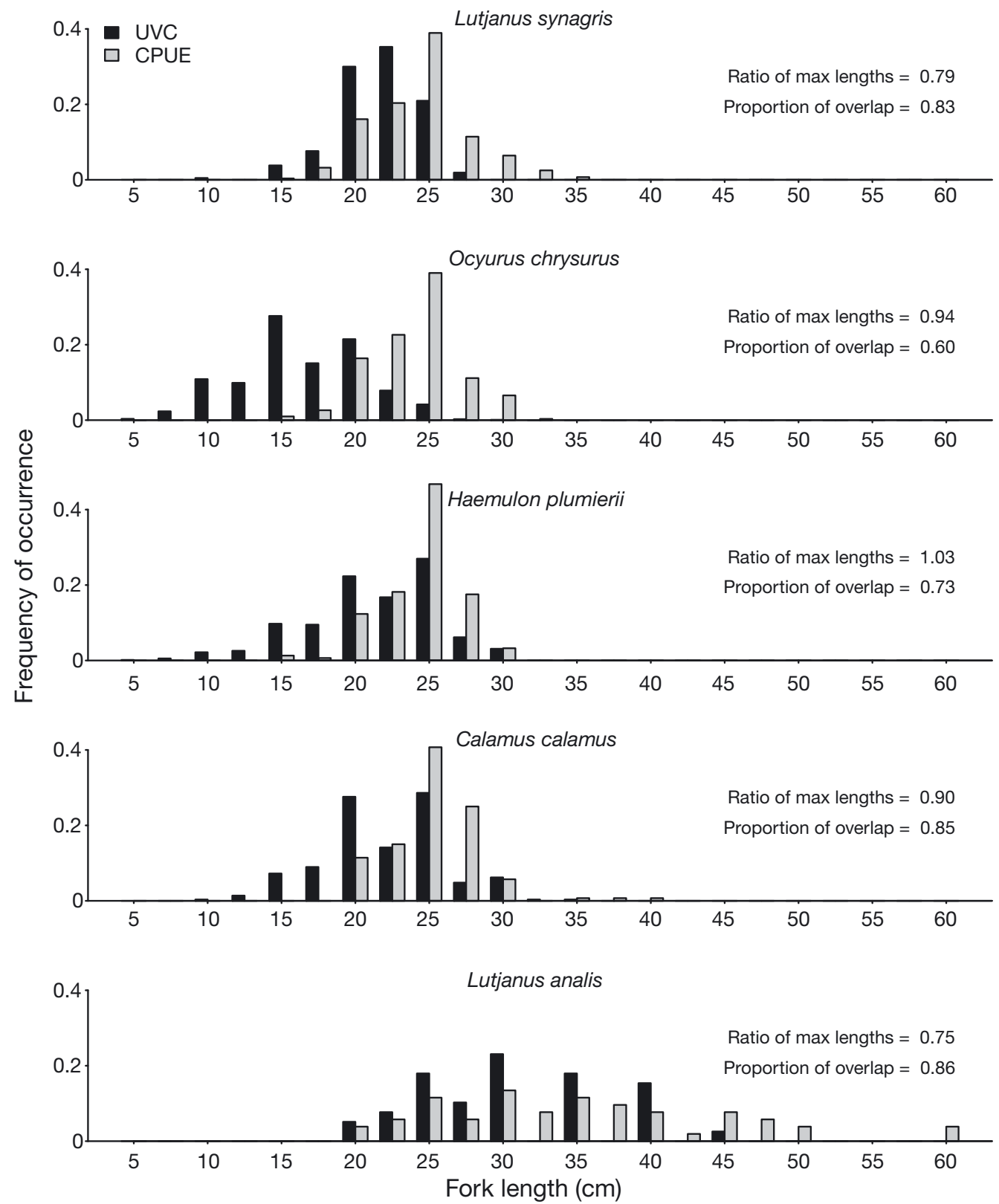

Fig. 2. Length frequency by species for individuals in catch-per-unit-effort (CPUE) and underwater visual census (UVC) data sets. Average lengths of fish caught in CPUE are significantly greater than average lengths observed in UVC for all species $(\mathrm{p}<0.001)$ except Lutjanus analis $(\mathrm{p}=0.02)$ 

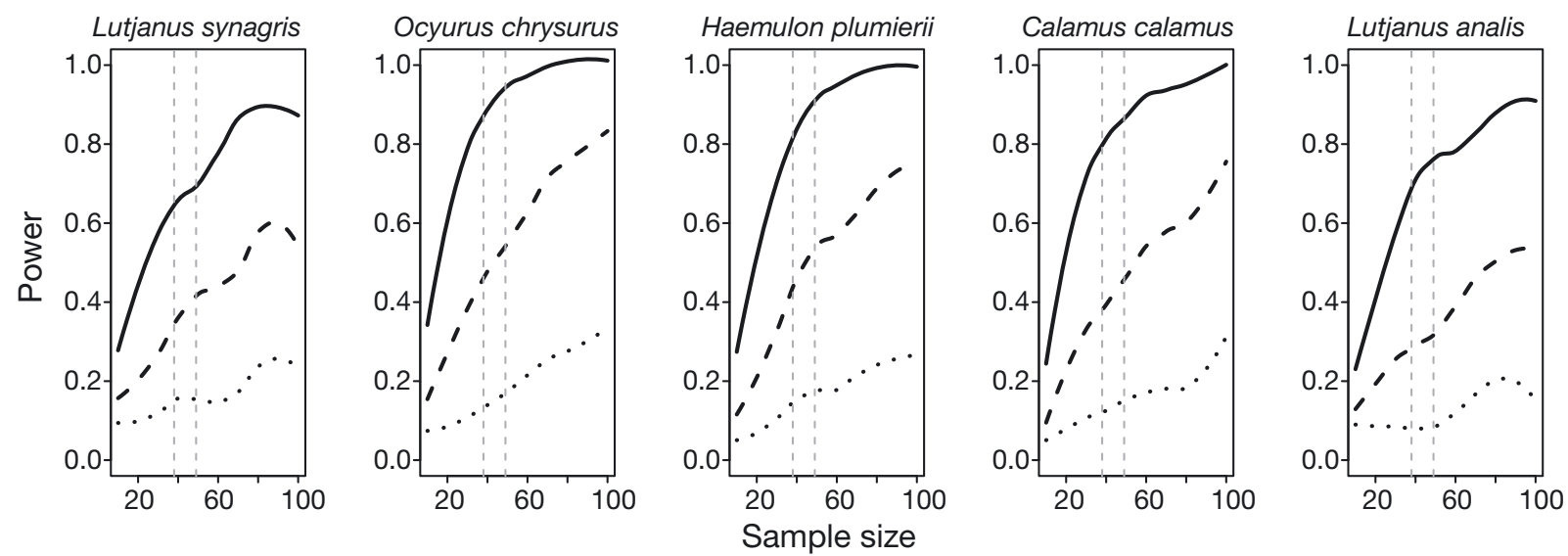

Fig. 3. Smoothed power curves for Spearman's correlation values of $r=0.50$ (solid line), $r=0.30$ (dashed line), and $r=0.10$ (dotted line). Vertical gray lines denote sample sizes used in the study ( $\mathrm{n}=38$ and 49 )

cantly correlated $(\mathrm{p}=0.19)$. For the same set of sites, when CPUE and UVC were collected at different times, neither abundance $(p=0.27)$ nor biomass $(p=$ $0.53)$ estimates were correlated.

When CPUE estimates of species composition in terms of abundance were compared to UVC estimates calculated from an average of 5 samples on different sides of the patch, the 2 measures were uncorrelated for abundance $\left(\mathrm{p}=0.39, \mathrm{r}^{2}=0.12\right)$ and biomass ( $\left.p=0.61, r^{2}=0.10\right)$. When CPUE estimates of abundance were compared to UVC estimates only from the side of the patch where fishing took place, correlation of abundance increased $\left(p=0.11, \mathrm{r}^{2}=\right.$ 0.16). For estimates of biomass from CPUE and UVC on the side of the patch closest to fishing, correlations were marginally significant $\left(\mathrm{p}=0.05, \mathrm{r}^{2}=0.18\right)$. Because patches were only 20 to $100 \mathrm{~m}$ in diameter, these results indicate that there are differences in community composition on scales of $<100 \mathrm{~m}$.

\section{Correlations in abundance at the same sites over time in UVC and CPUE}

Comparisons of abundance estimates within sampling methodologies indicated that temporal variability in this system was high for some species, while other species appeared to occur consistently at the same sites (Table 4). CPUE abundance estimates at the same sites from different sampling periods were only correlated for Lutjanus synagris and Ocyurus chrysurus. UVC estimates of abundance from different sampling periods were significantly correlated for L. synagris, Haemulon plumierii, and L. analis $(\mathrm{p}=0.03)$.
Table 4. p-values for Spearman's rank correlations of abundance estimates on different days, denoting strength of correlations in abundance at the same sites over 2 sample periods for each sampling methodology. CPUE: catch-perunit-effort, UVC: underwater visual census

\begin{tabular}{|lcr|}
\hline Species & CPUE & UVC \\
\hline Lutjanus synagris & $<0.001$ & $<0.01$ \\
Ocyurus chrysurus & 0.03 & 0.15 \\
Haemulon plumierii & 0.47 & $<0.01$ \\
Calamus calamus & 0.37 & 0.16 \\
Lutjanus analis & 0.09 & 0.03 \\
\hline
\end{tabular}

ANOSIM of the abundance estimates of all 5 species elucidated some of the factors responsible for lack of correlations between time periods. For the 65 CPUE sites where depth was recorded, ANOSIM showed that depth of the fishing site had a significant influence on the relative abundance of the 5 fish species $(p<0.01)$. ANOSIM of CPUE sites with multiple factors showed that the sampling period appeared to be the most influential factor in predicting the fish community $(p=0.001)$, followed by the date of sampling $(p=0.01)$. Weather conditions $(p=0.80)$, time of day $(\mathrm{p}=0.92)$, and fisher skill $(\mathrm{p}=0.21)$ were not found to be significant. ANOSIM of the UVC community composition also indicated that sampling period was the only significant factor differentiating relative abundances in the top 5 species $(p=0.02)$.

\section{Spatial autocorrelation}

Variograms confirmed that spatial autocorrelation could not be detected in any of the species at small 
spatial scales except for Lutjanus synagris, for which autocorrelation was higher at distances of $<500 \mathrm{~m}$ as indicated by a lower semivariance in the first distance bin (Fig. 4). For the other 4 species, the degree of variation between sites did not show a decrease at small distances, and there were no trends in semivariance across distances.

\section{Sample sizes}

Sample size that would be necessary to detect a 2fold change in abundance with a statistical power of 0.80 at the $\alpha=0.05$ significance level are reported for all species with occurrence rates greater than $5 \%$ (Table 5). The most commonly occurring species, Ocyurus chrysurus and Haemulon plumierii, required relatively few samples to detect significant changes (<20 UVC samples or $<40$ CPUE samples). Lutjanus synagris, which occurred more frequently in the CPUE data than in the UVC data, required 3 times as many UVC samples as CPUE samples to obtain the same statistical power. The less frequently occurring grouper species Epinephelus guttatus, E. cruentatus, and E. morio required greater numbers of CPUE than UVC samples to obtain the same statistical power.

\section{DISCUSSION}

We found estimates of abundance from hook-andline CPUE and UVC to be highly variable over small temporal and spatial scales. It is not surprising, then, that we also found that estimates of abundance from CPUE and UVC were usually not correlated, unless they were collected simultaneously and at very small spatial scales $(<100 \mathrm{~m})$. Biomass estimates were gen-

Table 5. Sample sizes required to detect $100 \%$ change in abundance with a statistical power of 0.80 at the $\alpha=0.05$ significance level. CPUE: catch-per-unit-effort, UVC: underwater visual census

\begin{tabular}{|lrr|}
\hline Species & CPUE & UVC \\
\hline Ocyurus chrysurus & 20 & 11 \\
Calamus calamus & 80 & 20 \\
Lutjanus synagris & 86 & 258 \\
Haemulon plumierii & 34 & 18 \\
Lutjanus analis & 74 & 48 \\
Epinephelus guttatus & 357 & 56 \\
Epinephelus cruentatus & 168 & 96 \\
Epinephelus morio & 127 & 101 \\
& & \\
\hline
\end{tabular}
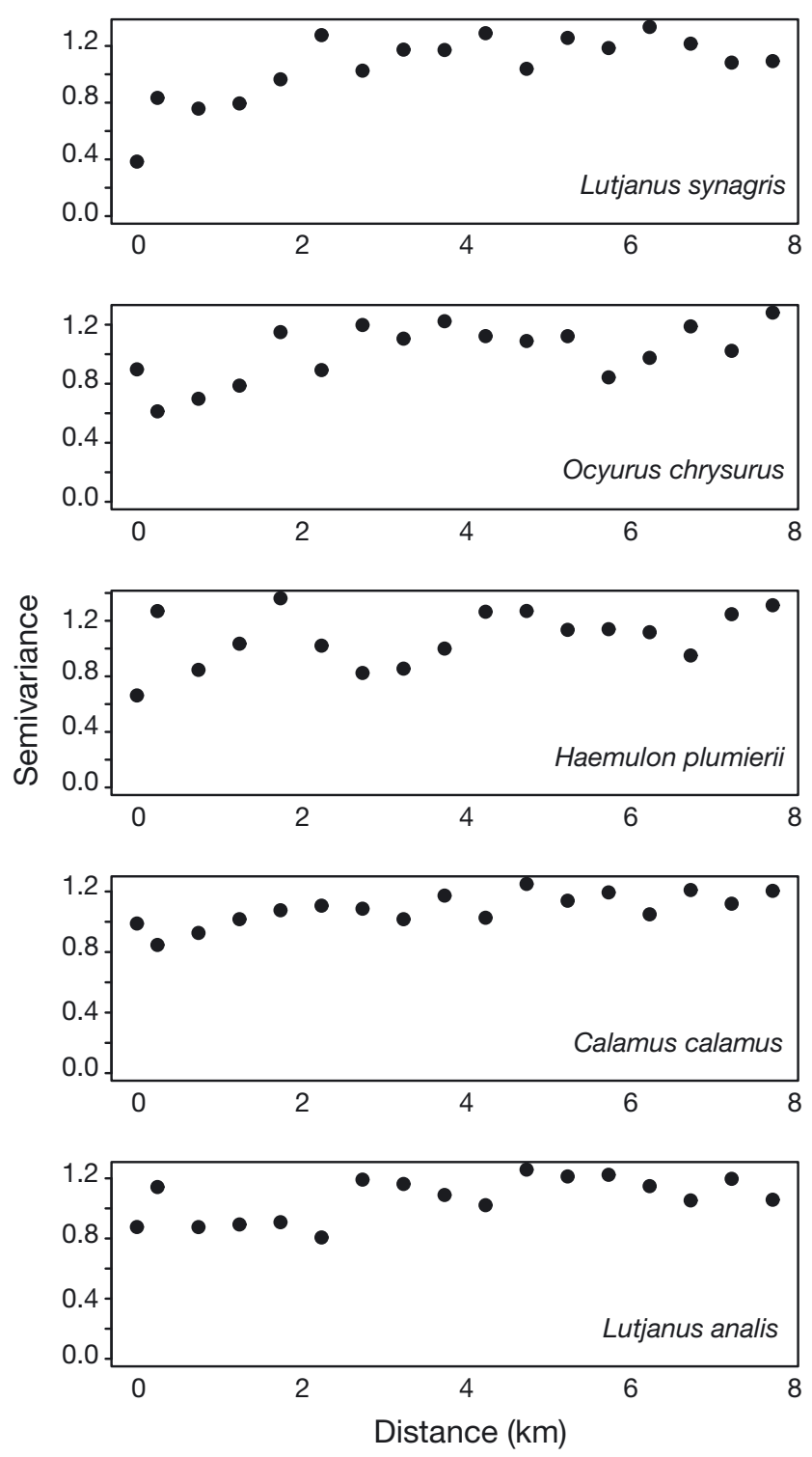

Fig. 4. Semivariograms for the 5 most abundant species in catch data, based on the classical method of moments estimator with $500 \mathrm{~m}$ bins

erally less correlated than abundance estimates, due to differences in size selectivity between the UVC and CPUE methods. Spatial autocorrelation was largely undetectable in this complex, heterogeneous patch reef system, and likely occurs only at scales below those that we considered. Variation among sampling periods was responsible for the greatest amount of variation in community composition measured by both CPUE and UVC methods.

The sizes of fishes targeted by the CPUE and UVC methodologies clearly differed, with larger size 
classes appearing in the catch. Unexpectedly, accounting for the differences in size selectivity between CPUE and UVC did not increase correlations between abundance estimates from the 2 methods. These results suggest that the larger fish appearing in the CPUE data were not actually a subset of those observed in the UVC. Most likely, the presence of bait attracted larger-sized fish that had been foraging in the deeper waters that flanked the edges of most patch reefs (an area that was not included in the UVC sampling area), and these individuals may have returned to their original positions once the bait was removed from the water and the diver was present in the immediate area. Furthermore, there is evidence that fleeing response increases with fish size, and thus detectability in the UVC will also vary according to length (Bozec et al. 2011). Due to the attractive force of fishing bait and biases associated with diver avoidance, UVC and CPUE methods may not assess the same fish community, even when they are carried out in the same location.

Across multiple temporal scales, UVC and CPUE estimates of abundance were correlated for only 2 snapper species: Lutjanus synagris and Ocyurus chrysurus. However, L. synagris estimates of abundance were only correlated when CPUE and UVC were collected on different days, whereas $O$. chrysurus estimates were only correlated when CPUE and UVC were collected simultaneously. These results are most likely due to behavioral differences between these 2 species. While no specific behaviors of $L$. synagris with respect to divers have been noted, $O$. chrysurus is known to be attracted to divers (Bohnsack \& Bannerot 1986). If O. chrysurus are attracted to both fishing bait and divers, then it would be expected that estimates of abundance from CPUE and UVC would be highly correlated when the 2 methods are used simultaneously.

The finding that estimates of Lutjanus synagris abundance were only correlated when CPUE and UVC were collected on different days suggests that the presence of divers had some effect on the species. Divers may drive schools away from the patch so that they are not attracted to the nearby bait, or they may affect the feeding behavior of the fish and reduce catch rates. L. synagris is also noteworthy in that it was the only species to have nearly equal occurrence rates in the CPUE and $\mathrm{UVC}_{\text {; }}$ in other words, it appeared as frequently in the catch as it was seen underwater. This could indicate that this species is more highly mobile than other species, and/or that the species is highly attracted to bait. It was also the only species that showed some degree of autocorre- lation at distances $<500 \mathrm{~m}$, which further supports the idea that the species is highly mobile. In an acoustic telemetry study, Friedlander \& Monaco (2007) found that $L$. synagris made very predictable diel movements of $>500 \mathrm{~m}$, but consistently returned to the same reef habitat during daytime hours. Similarly, our results also suggested that $L$. synagris appeared to have relatively high site fidelity; estimates of abundance at the same sites were highly correlated over different time periods for both CPUE and UVC methods. Together, these findings suggest that schools of $L$. synagris remain generally attached to an area during daytime hours, but show high mobility and can easily move to or from neighboring patch reefs when disturbed by a diver or attracted to bait.

While estimates of abundance from UVC and CPUE were strongly correlated for 2 of the lutjanid species, they were only weakly correlated for Lutjanus analis. Farmer \& Ault (2011) reported that $L$. analis makes short, frequent (scales of minutes) movements of up to $500 \mathrm{~m}$, and Lindholm et al. (2005) showed that Ocyurus chrysurus also regularly moved back and forth from sites $500 \mathrm{~m}$ apart at 15 min intervals. As all 3 lutjanids appear to display similar movement abilities, differences in observed correlations between sampling methods may be affected by schooling behavior. Robichaud et al. (2000) showed that more mobile fish species had greater catchability rates in traps. The behavior of large schools exhibited by $L$. synagris and $O$. chrysurus may have been responsible for the highly significant correlations between CPUE and UVC estimates for these species, as compared to weak correlations exhibited by the more solitary $L$. analis. Estimates of abundance from CPUE and UVC were not correlated for Haemulon plumierii or Calamus calamus. Tulevech \& Recksiek (1994) reported that while $H$. plumierii make extensive nocturnal foraging migrations, they tend to stay within a $100 \mathrm{~m}$ home range during the day. Friedlander \& Monaco (2007) reported movements of a single C. calamus individual, which was highly attached to a site. Thus, it appears that correlations between UVC and CPUE may only occur for moderately mobile species, and that schooling behavior may increase the strength of correlations between the 2 sampling methods.

The lack of spatial autocorrelation observed for most species in this study is unexpected, and may be due the high level of heterogeneity in our study system. We observed that habitats were widely variable within the extent of individual patches, and this appeared to be a result of the prevailing southward 


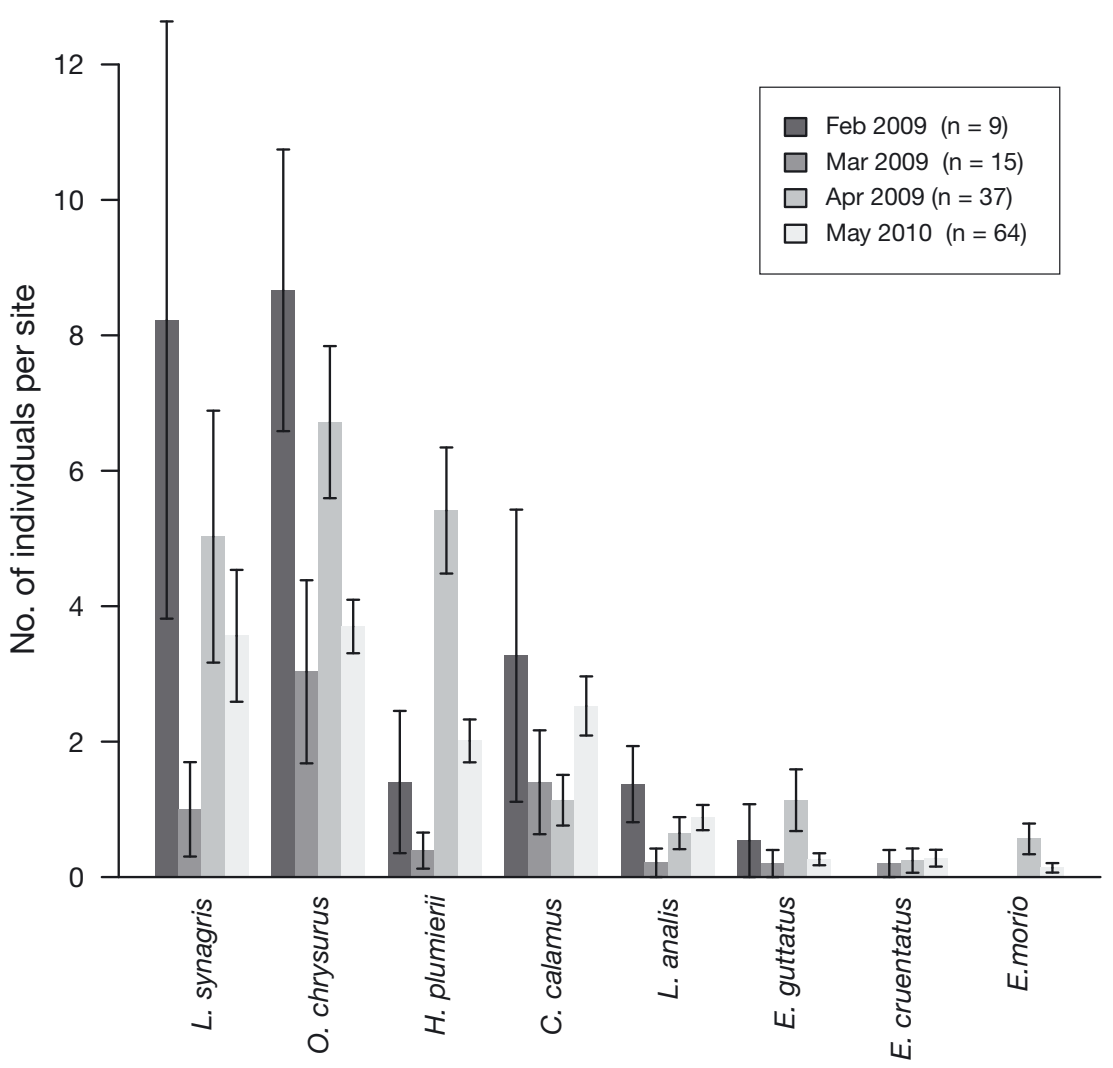

Fig. 5. Mean fish $( \pm \mathrm{SE})$ abundance by species and sampling period from catch-per-unit-effort (CPUE) data collected at randomly selected sites

Temporal variability in our study system also appeared to be high, as there were no significant correlations between replicate estimates of abundance using the same method for some species. Of the factors we tested, the sampling period during which data collection occurred was the most significant factor influencing community composition in both the CPUE data and UVC data. All of our CPUE and UVC sampling was conducted during the months of February to May, and therefore we were unable to resolve seasonal differences in community composition. The effect of month or season on community composition should be large, given that many reef fishes undertake large migrations to spawning sites at different times of the year. At Glover's Reef, grouper species, particularly Epinephelus striatus, $\mathrm{Myc-}$ teroperca bonaci, and $M$. venenosa, migrate outside the lagoon to the forereef in the winter months (Starr et al. 2007), while snappers have been documented to spawn during the

current flow through the lagoon. When exposed to certain environmental conditions, patch reefs can develop windward-leeward margins, whereby the high energy windward zone becomes dominated by encrusting organisms, and sediments are deposited on the leeward side of the patch due to wave refraction (Wright \& Burchette 1996). We noted that on most survey patches, the greatest amount of coral cover occurred on the northern (upcurrent) side, whereas the southern (leeward) sides of the patches tended to be composed of sand and seagrass, sometimes with no coral cover at all. Fish composition also varied widely according to location around the patch, with increased diversity and abundance of fishes tending to occur around the morphologically complex northern sides of the patches. We suspect that spatial autocorrelation might be present on finer scales than those that we could analyze, or it is possible that we did not have sufficient sample sizes to detect autocorrelation. Spatial autocorrelation might be more easily detected on more homogeneous reef systems such as continuous fringing or barrier reefs. In such systems, we might also expect correlations between CPUE and UVC to occur over larger spatial scales. spring and summer months (Heyman \& Requena 2002). Our results show that estimates made at a single point in time, or those made during the same season in different years, may not capture the full extent of variability in fish community composition in the system (Fig. 5). If fishery managers wish to obtain accurate estimates of mean abundance, they would be advised to complete sampling over multiple time periods.

Previous works have shown that estimates of abundance from CPUE and UVC are often in agreement when analyses are conducted over broad spatial scales (Jennings \& Polunin 1995, Willis et al. 2000) or based on total density and biomass estimates (Kulbicki et al. 2000). However, correlations between different abundance estimation methods may break down when analyzed on smaller spatial scales, or at the species level. Our results corroborate findings from the few other studies that have compared underwater visual surveys with catch data on these finer scales. Ralston et al. (1986) found a positive but insignificant relationship between abundance of species assessed by a submersible and CPUE from experimental angling, but the 2 surveys were done in different months. Haggarty \& King (2006) found a 
proportional relationship between UVC and CPUE surveys carried out almost simultaneously for 2 out of 4 study species, and suggested that behavioral differences were responsible for the lack of proportionality for some species. Kulbicki (1988) also suggested that relationships between UVC and CPUE depend on behavior; proportionality was not observed for an inconspicuous species in their study. Our results concur with these previous findings and show that UVC and CPUE may be correlated when collected simultaneously, but that this relationship weakens when temporal or spatial variability is introduced. Additionally, our results suggest that behavioral differences, particularly related to species mobility and schooling behavior, may be responsible for a lack of proportionality between CPUE and UVC estimates for some species.

CPUE was not adequate for assessing the diversity of the full fish community, as only one-third of the species observed in the UVC appeared in the catch. The UVC method is advantageous in that it can detect both commercial and non-commercial species, and in particular smaller and more cryptic species. Many of the more commercially valuable species (e.g. groupers) had low occurrence rates in the UVC and also had high relative selectivities. Thus, CPUE may be useful for monitoring commercially important and/or rare species, or to detect pelagic or deepwater species not normally assessed by UVC. Some species in our study could be efficiently assessed with CPUE, as they required smaller or approximately equal sample sizes to detect statistically significant changes. In our study, the CPUE method was also more time- and cost-effective; 3 CPUE samples could be completed in the time it took to complete a single UVC sample. Depending on the species of interest, both UVC and CPUE methodologies could provide useful information for assessments of fish abundance.

Many coral reefs are located in developing countries, where funding for management of these sensitive ecosystems is limited (Graham et al. 2005). Given that the livelihoods of many coastal populations depend on healthy reef resources (Donner \& Potere 2007), there is a need to develop efficient and costeffective management strategies for reef fisheries. UVC can be useful to detect a wide diversity of fishes, while estimating abundances of fish stocks using CPUE in shallow coral reef ecosystems can be advantageous because the method is efficient, lowcost, and requires little technical knowledge or skill. If both UVC and CPUE methods are biased, it may be preferable to use CPUE for assessments, because this method is more likely to sample the population targeted by fishing. Based on our findings, however, we concur with previous studies which have suggested that monitoring may be most effectively conducted using a combination of sampling techniques (Murphy \& Jenkins 2010). Further research should be done to understand the biases associated with each of these methods in estimation of true fish abundances. Given the high spatial and temporal variability inherent in reef systems, it is also advisable to conduct studies to determine minimum sampling sizes before attempting to analyze data to detect changes in ecosystems. Inadequate sample sizes will result in an inability to detect trends and a failure to assess the impacts of management efforts. Effective monitoring is an important step towards stemming the rapid degradation of coral reef fisheries and associated ecosystems occurring worldwide.

Acknowledgements. This study was funded by the Pew Institute for Ocean Science at the University of Miami. M.K. was supported by a University of Miami Graduate Fellowship and funding from the Cooperative Institute for Marine and Atmospheric Studies while completing this work. We acknowledge the Wildlife Conservation Society, B. Huntington, and L. Chérubin for their assistance in completing field work, and J. Walter for helpful discussions on statistical analyses. We also thank R. Nuñez for his patience while fishing for many hours at randomly generated sites where there were no fish.

\section{LITERATURE CITED}

Acosta A (1997) Use of multi-mesh gillnets and trammel nets to estimate fish species composition in coral reef and mangroves in the southwest coast of Puerto Rico. Caribb J Sci 33:45-57

Acosta CA, Robertson DN (2002) Diversity in coral reef fish communities: the effects of habitat patchiness revisited. Mar Ecol Prog Ser 227:87-96

Anderson MJ (2001) A new method for non-parametric multivariate analysis of variance. Austral Ecol 26:32-46

Beger M, Possingham HP (2008) Environmental factors that influence the distribution of coral reef fishes: modeling occurrence data for broad-scale conservation and management. Mar Ecol Prog Ser 361:1-13

Bell JD, Galzin R (1984) Influence of live coral cover on coral-reef fish communities. Mar Ecol Prog Ser 15: 265-274

Bennett RH, Gotz A, Sauer WHH, Cowley PD, Palmer RM (2009) Optimisation of underwater visual census and controlled angling methods for monitoring subtidal temperate reef fish communities. Afr J Mar Sci 31: 277-287

Bohnsack JA, Bannerot S (1986) A stationary visual census technique for quantitatively assessing community structure of coral reef fishes. NOAA Tech Rep NMFS 41. National Marine Fisheries Service, Silver Spring, MD 
Bohnsack JA, Harper DE (1988) Length-weight relationships of selected marine reef fishes from southeastern United States and the Caribbean. NOAA Tech Memo NMFS-SEFC-215. National Marine Fisheries Service, Southeast Fisheries Center, Miami, FL

Bordalo-Machado P (2006) Fishing effort analysis and its potential to evaluate stock size. Rev Fish Sci 14:369-393

Bozec YM, Kulbicki M, Laloë F, Mou-Tham G, Gascuel D (2011) Factors affecting the detection distances of reef fish: implications for visual counts. Mar Biol 158:969-981

Clarke KR (1993) Non-parametric multivariate analyses of changes in community structure. Aust J Ecol 18: $117-143$

Connell SD, Samoilys MA, Lincoln Smith MP, Leqata J (1998) Comparisons of abundance of coral-reef fish: catch and effort surveys vs visual census. Aust J Ecol 23: 579-586

Diggle PJ, Ribeiro PJ (2007) Model-based geostatistics. Springer, New York, NY

$>$ Donner SD, Potere D (2007) The inequity of the global threat to coral reefs. Bioscience 57:214-215

> Eros T, Specziar A, Biro P (2009) Assessing fish assemblages in reed habitats of a large shallow lake: a comparison between gillnetting and electric fishing. Fish Res 96: 70-76

Faith DP, Minchin PR, Belbin L (1987) Compositional dissimilarity as a robust measure of ecological distance. Vegetatio 69:57-68

Farmer NA, Ault JS (2011) Grouper and snapper movements and habitat use in Dry Tortugas, Florida. Mar Ecol Prog Ser 433:169-184

Friedlander AM, Monaco ME (2007) Acoustic tracking of reef fishes to elucidate habitat utilization patterns and residence times inside and outside marine protected areas around the island of St. John, USVI. NOAA Tech Memo NOS NCCOS 63. National Ocean Service, Center for Coastal Monitoring and Assessment, Biogeography Branch, Silver Spring, MD

Garcia Charton JA, Perez Ruzafa A, Sanchez Jerez P, Bayle Sempere JT, Renones O, Moreno D (2004) Multi-scale spatial heterogeneity, habitat structure, and the effect of marine reserves on western Mediterranean rocky reef fish assemblages. Mar Biol 144:161-182

Gischler E, Hudson JH (1998) Holocene development of three isolated carbonate platforms, Belize, Central America. Mar Geol 144:333-347

Graham NAJ, Dulvy NK, Jennings S, Polunin NVC (2005) Size-spectra as indicators of the effects of fishing on coral reef fish assemblages. Coral Reefs 24:118-124

Grober-Dunsmore R, Frazer TK, Beets JP, Lindberg WJ, Zwick P, Funicelli NA (2008) Influence of landscape structure on reef fish assemblages. Landsc Ecol 23:37-53

> Haggarty DR, King JR (2006) CPUE as an index of relative abundance for nearshore reef fishes. Fish Res 81:89-93

> Harborne AR, Mumby PJ, Kappel CV, Dahlgren CP and others (2008) Reserve effects and natural variation in coral reef communities. J Appl Ecol 45:1010-1018

> Harley SJ, Myers RA, Dunn A (2001) Is catch-per-unit-effort proportional to abundance? Can J Fish Aquat Sci 58: 1760-1772

> Harvey E, Fletcher D, Shortis MR, Kendrick GA (2004) A comparison of underwater visual distance estimates made by scuba divers and a stereo-video system: implications for underwater visual census of reef fish abundance. Mar Freshw Res 55:573-580
Hawkins JP, Roberts CM, Gell FR, Dytham C (2007) Effects of trap fishing on reef fish communities. Aquat Conserv 17:111-132

Heyman W, Requena N (2002) Status of multi-species spawning aggregations in Belize. The Nature Conservancy, Punta Gorda

Huntington BE, Karnauskas M, Babcock EA, Lirman D (2010) Untangling natural seascape variation from marine reserve effects using a landscape approach. PLoS ONE 5:e12327

Januchowski-Hartley FA, Graham NAJ, Feary DA, Morove T, Cinner JE (2011) Fear of fishers: Human predation explains behavioral changes in coral reef fishes. PLoS ONE 6:e22761

> Jennings S, Polunin NVC (1995) Biased underwater visual census biomass estimates for target-species in tropical reef fisheries. J Fish Biol 47:733-736

Kulbicki M (1988) Correlation between catch data from bottom longlines and fish censures in the SW lagoon of New Caledonia. Proc 6th Int Coral Reef Symp 2:305-312

Kulbicki M, Labrosse P, Letourneur Y (2000) Fish stock assessment of the northern New Caledonian lagoons: 2 Stocks of lagoon bottom and reef-associated fishes. Aquat Living Resour 13:77-90

> Lehr R (1992) Sixteen $S$-squared over $D$-squared: a relation for crude sample size estimates. Stat Med 11:1099-1102

Lindholm J, Kaufman L, Miller S, Wagschal A, Newville M (2005) Movement of yellowtail snapper (Ocyurus chrysurus Block 1790) and black grouper (Mycteroperca bonaci Poey 1860) in the northern Florida Keys National Marine Sanctuary as determined by acoustic telemetry. Marine Sanctuaries Conservation Series MSD-05-4. National Ocean Service, Office of Ocean and Coastal Resource Management, Marine Sactuaries Division, Silver Spring, $\mathrm{MD}$

MacNeil MA, Graham NAJ, Conroy MJ, Fonnesbeck CJ and others (2008) Detection heterogeneity in underwater visual-census data. J Fish Biol 73:1748-1763

McClanahan TR, Graham NAJ, Maina J, Chabanet P, Bruggemann JH, Polunin NVC (2007) Influence of instantaneous variation on estimates of coral reef fish populations and communities. Mar Ecol Prog Ser 340: 221-234

McCune B, Grace JB (2002) Analysis of ecological communities. MjM Software, Gleneden Beach, OR

> Modarres R (1996) Bootstrap power of the generalized correlation coefficient. Stat Comput 6:139-145

> Murphy HM, Jenkins GP (2010) Observational methods used in marine spatial monitoring of fishes and associated habitats: a review. Mar Freshw Res 61:236-252

Pittman SJ, Costa BM, Battista TA (2009) Using lidar bathymetry and boosted regression trees to predict the diversity and abundance of fish and corals. J Coast Res 53(Spec Issue):27-38

Ralston S, Gooding RM, Ludwig GM (1986) An ecological survey and comparison of bottom fish resource assessments (submersible versus handline fishing) at Johnston Atoll. Fish Bull 84:141-156

Richards L, Schnute J (1986) An experimental and statistical approach to the question: Is CPUE an index of abundance? Can J Fish Aquat Sci 43:1214-1227

Robichaud D, Hunte W, Chapman M (2000) Factors affecting the catchability of reef fishes in Antillean fish traps. Bull Mar Sci 67:831-844

Sobel JA, Dahlgren CP (2004) Marine reserves: a guide to 
science, design, and use. Island Press, Washington, DC Starr RM, Sala E, Ballesteros E, Zabala M (2007) Spatial dynamics of the Nassau grouper Epinephelus striatus in a Caribbean atoll. Mar Ecol Prog Ser 343:239-249

Tulevech SM, Recksiek CW (1994) Acoustic tracking of adult white grunt, Haemulon plumieri, in Puerto Rico and Florida. Fish Res 19:301-319

Willis TJ, Millar RB, Babcock RC (2000) Detection of spatial variability in relative density of fishes: comparison of

Editorial responsibility: Janet Ley,

St. Petersburg, Florida, USA visual census, angling, and baited underwater video. Mar Ecol Prog Ser 198:249-260

Wright VP, Burchette TP (1996) Shallow-water carbonate environments. In: Reading HG (ed) Sedimentary environments: processes, facies, and stratigraphy. Blackwell Science, Cornwall

> Ye Y, Dennis D (2009) How reliable are the abundance indices derived from commercial catch-effort standardization? Can J Fish Aquat Sci 66:1169-1178

Submitted: July 15, 2011; Accepted: August 14, 2012 Proofs received from author(s): November 4, 2012 